\title{
Tabus ansprechen
}

\section{Sexuelle Lust ist keine Frage des Alters}

\author{
Sex im Alter wird noch immer tabuisiert, dabei legt gerade die Nach- \\ kriegsgeneration viel Wert auf ein erfülltes Sexualleben. Ärzte sollten \\ daher auch die Auswirkungen ihrer Therapie auf die Sexualfunktion \\ berücksichtigen - und mit den Patienten darüber reden.
}

$\mathrm{E}$ n Betablocker und ein starkes Analgetikum bei einem Diabetiker kein Wunder, dass da im Bett nichts mehr läuft. „Es gibt beängstigend viele Medikamente, die die Sexualität beeinflussen können“, so Dr. Rainer Kortus, ehemaliger Chefarzt der Abteilung für Gerontopsychiatrie am Zentrum für Psychiatrie Winnenden. Ärzte würden sich jedoch darüber meist keine Gedanken machen: Noch immer werde davon ausgegangen, dass mit dem Alter das sexuelle Verlangen zurückgeht und Sex bei über 80-Jährigen praktisch nicht mehr stattfindet. Dass letzteres häufig der Fall sei, liege nicht an mangelnder Lust, sondern eher an fehlenden Gelegenheiten und gesundheitlichen Einschränkungen.

Bei der Nachkriegsgeneration, den heute 70-Jährigen, sei der Wunsch nach Sexualität deutlich höher als früher: Pille und sexuelle Befreiung hätten hier ihre Spuren hinterlassen. In Umfragen zeigten $66 \%$ der Frauen und $80 \%$ der Männer bis Mitte 70 ein Interesse an Sexualität, zwei Drittel der Frauen über 60 berichteten über erotische Träume, 90\% der Männer über erotische Fantasien.

\section{Die Kluft zwischen Wunsch und Wirklichkeit}

Im höheren Alter klaffen Wunsch und Wirklichkeit jedoch weit auseinander. Nach einer Untersuchung im Jahr 2001 wünschen sich etwa $60 \%$ der Männer und $50 \%$ der Frauen im Alter von über 75 Jahren noch Geschlechtsverkehr, aber nur 30\% der Männer und 10\% der Frauen können sich den Wunsch erfüllen.

Neben einem fehlenden Partner machen alten Menschen vor allem Erkrankungen zu schaffen. So führen KHK, Hypertonie und Diabetes bei Männern häufig zu einer erektilen Dysfunktion, diese tritt nicht selten auch nach einer Prostatektomie auf. Bei Frauen kommt

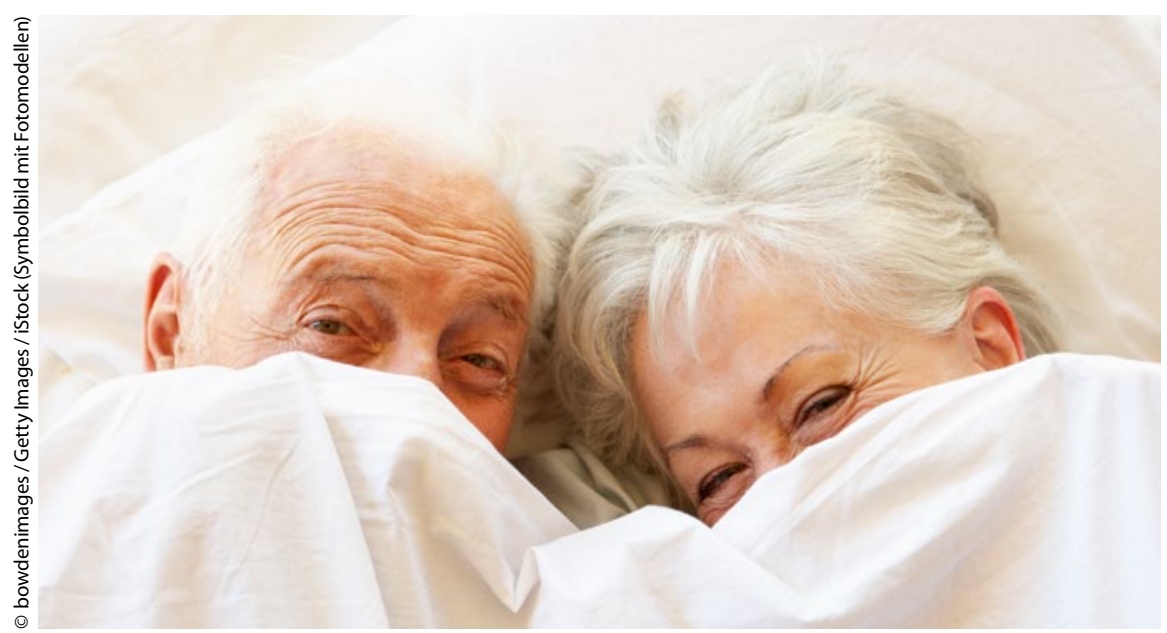

Sexualität: für viele alte Menschen ein - unerfüllter - Traum.

es nach der Menopause zur Atrophie der Vaginalschleimhaut mit reduzierter Lubrikation, was Schmerzen beim Koitus begünstigt. Auch eine Harninkontinenz beeinträchtigt das Sexualleben.

Indem Ärzte solche Leiden angehen, könnten sie viel zur sexuellen Zufriedenheit ihrer Patienten beitragen. Wichtig sei daher, die Auswirkungen einer Behandlung auf die Sexualität - im Positiven wie im Negativen - im Blick zu haben und das Thema taktvoll anzusprechen.

\section{Entsexualisierende Bekleidung in Pflegeheimen}

Noch schwerer mit ihren sexuellen Wünschen haben es Demenzpatienten oder ältere Menschen in Pflegeheimen. Die gesellschaftliche Entwertung alter Menschen führe dazu, dass solche Wünsche nicht ernst genommen würden und Pflegekräfte oft hilflos reagierten, wenn sie mit „peinlichen“ Situationen konfrontiert würden, so Kortus. In den meisten Pflegeeinrichtungen herrschten „sexualfeindliche Bedingungen“. So würden schöne Unterwäsche oder Kosmetika als Unsinn bezeichnet, entsexualisierende Kleidung, etwa der Jogginganzug, spiegele wohl die Einstellung der Pflege zur Sexualität wider. Von der häufig romantisierten „befreiten Alterssexualität“ sei in Heimen also nichts zu spüren.

Ärzte und Pfleger sollten sich im Klaren sein, dass die sexuelle Lust im hohen Alter nicht zwangsläufig zurückgehe. Kortus zitierte eine 82-Jährige, die zu ihren sexuellen Empfindungen befragt worden war: „Ich habe mein ganzes Leben lang die Vorstellung gehabt, wenn der Sex aufhört, hört das Leben auf. Doch er ist immer da, in Form von Träumen, von Vorstellungen, von Onanie. Es ist keinesfalls so, dass man müde wird und einen die Lust verlässt. Gott sei Dank.“

Thomas Müller

29. Jahreskongress der Deutschen Gesellschaft für Geriatrie (DGG), 28.-30. September, Frankfurt am Main. 